\title{
ISU PENDIDIKAN WANITA MELAYU DALAM AKHBAR DAN MAJALAH MELAYU, 1920-an HINGGA 1940-an
}

\author{
Hasnah Binti Hussiin
}

\begin{abstract}
Women play significant roles in the country's development. Changing times have also changed the roles and status of women. Women are now involved in various sectors instance such as the economy, politics and social activities. Also, women are more outstanding able to challenge men in several areas. Educatian is the main factor that has brought about this change. If we were to look at the roles and status of women before independence, it is clear they were not given the opportunity to achieve the highest level of education. Their roles were more than being mothers and wives. Those who were educated, were very small in numbers compared to men or foreigners. The conventional way of thinking of the Malays at that point of time made it more difficult and hence, they became isolated from the modern development. However, the newspapers and magazines that were published at that time played significant roles in channelling the ideas for development to the Malays generally and to the Malay women specifically. This article will discuss the achievement of the Malay women in the field of education during the colonial period.
\end{abstract}

\section{Pengenalan}

Perbincangan mengenai wanita dalam sejarah Tanah Melayu bukanlah satu perkara baru. Ini memandangkan perbincangan mengenai kedudukan wanita secara umumnya telah pun dibincangkan sejak awal 
abad ke-19 oleh Abdullah Munshi pada tahun 1850-an dalam Hikayat Abdullah. Beliau menceritakan tentang kedudukan dan peranan wanita Melayu di zaman ini yang sudah bebas daripada pengaruh tradisi. Malah, terdapat juga di antara wanita pada masa ini yang telah keluar rumah bagi membantu suami mereka mencari rezeki. ${ }^{1}$ Selain Abdullah Munsyi, memasuki era awal abad ke-20, Syed Sheikh Al-Hadi pula membawa isu-isu wanita di dalam tulisannya yang dimuatkan di dalam majalah Al-Ikhwan dan Al-Imam. Tidak dinafikan bahawa keduadua tokoh ini telah membawa inspirasi kepada penulis selepasnya untuk membincangkan mengenai wanita di dalam tulisan mereka terutamanya di dalam akhbar dan majalah sekitar 1920-an hingga akhir 1930-an seperti Panduan Guru, Majalah Guru, Saudara, Cenderamata, Bulan Melayu serta Warta Malaya.

\section{Isu Mengenai Pendidikan}

Secara umunya, perbincangan mengenai kedudukan dan peranan wanita Melayu sebelum merdeka telah dibincang secara meluas di dalam majalah Al-Imam. Majalah Al-Imam yang diterbitkan dari tahun 1906-1908 antaranya membincangkan tentang isu pendidikan wanita Melayu yang memperjuangkan agar wanita Melayu juga diberikan hak pendidikan yang sama dengan kaum lelaki. Al-Imam menekankan pendidikan amat penting diberikan kepada kaum wanita memandangkan peranan mereka sebagai pendidik kepada anak-anak bangsanya. ${ }^{2}$ Antara pendidikan yang perlu diberikan kepada wanita Melayu pada masa ini ialah ilmu agama, kesusilaan dan matematik.

Selain Al-Imam, pada tahun 1920-an diterbitkan pula Majalah Malaya di Pulau Pinang oleh Mohd Yunus Abdul Hamid (1926-1927). Walau bagaimanapun, majalah ini seakan tidak sealiran dengan majalah Al-Imam kerana dalam majalah tersebut, terdapat kenyataan bahawa wanita Melayu tidak boleh disamakan dengan kaum lelaki dalam semua aspek kerana sifat semulajadi kaum wanita yang sememangnya tidak sama dengan lelaki. Oleh itu, Majalah Malaya menganjurkan agar jabatan-jabatan kerajaan dan jabatan lain tidak perlu menggunakan khidmat kaum wanita kerana berpendapat tugas kaum wanita hanya duduk di rumah sahaja sebagai ibu dan isteri dalam rumahtangga dan tidak lebih dari itu. ${ }^{3}$

Pada tahun 1926, muncul pula majalah Al-Ikhwan di Pulau Pinang oleh Syed Sheikh Al-Hadi. Pada masa ini, beliau telah diberi gelaran sebagai pejuang feminisme di Tanah Melayu kerana tulisannya banyak ke arah menyedarkan kaum wanita dan memperjuangkan nasib wanita agar membebaskan diri daripada belenggu adat-adat lama yang menyebabkan wanita Melayu menjadi jahil dan tertinggal dari arus 
kemodenan. Dalam hal ini, Syed Sheikh Al-Hadi berpegang kepada asas bahawa kemajuan sesebuah negara itu sangat bergantung kepada kerjasama yang erat antara lelaki dan wanita. Kaum wanita diumpamakan sebagai pembantu kepada kaum lelaki terutamanya dalam usaha membangunkan negara dan bangsa. ${ }^{4}$

Perbincangan tentang kedudukan kaum wanita dibincangkan dengan lebih rancak lagi dengan terbitnya majalah Panduan Guru diikuti oleh Majalah Guru dan perdebatan paling hangat ialah pada tahun 1930-an dengan munculnya majalah Bulan Melayu. ${ }^{5}$ Dengan kemunculan Bulan Melayu ini, perjuangan memajukan wanita Melayu telah dibincangkan dengan lebih meluas lagi. Sebagaimana yang telah dibangkitkan oleh golongan reformis sebelum ini, Ibu Zain turut menyambung perjuangan golongan tersebut bagi mewakili kaum wanita seluruh Tanah Melayu untuk bangkit membebaskan kaum wanita dari belenggu adat-adat lama dan sekaligus membuka minda mereka untuk terus maju dalam dunia moden pada waktu itu.

Majalah Bulan Melayu merupakan majalah yang muncul dalam tempoh 1930-1938 dan diterbitkan di Johor Bahru oleh Persekutuan Perempuan Melayu Johor. Kebanyakan ahli-ahlinya terdiri daripada golongan guru-guru perempuan Melayu. Kemunculan majalah Bulan Melayu ini seiring dengan majalah dan akhbar Melayu yang terkenal seperti Warta Malaya, Majlis dan Lembaga. Isu-isu yang dibangkitkan dalam akhbar dan majalah Melayu ini berkisar tentang pendidikan Melayu, keagamaan, ekonomi, berita luar negara, hak-hak bangsa Melayu serta kesedaran kebangsaan. Dalam hal ini, Bulan Melayu juga tidak ketinggalan membincangkan isu-isu tersebut tetapi lebih memfokuskan kepada perjuangan memartabatkan kaum Wanita Melayu dalam pelbagai aspek seperti pendidikan, ekonomi dan sosial. Perbezaan antara majalah ini dengan akhbar serta majalah lain ialah majalah ini disunting oleh golongan wanita yang diketuai oleh Ibu Zain. $^{6}$

Kemunculan majalah Bulan Melayu adalah atas kesedaran guruguru wanita Melayu khususnya di negeri Johor terhadap kedudukan kaum wanita pada ketika itu yang terpinggir dari kemajuan sekiranya dibandingkan dengan bangsa lain terutamanya kaum Cina. Mereka merasakan nasib kaum wanita Melayu pada ketika itu perlu diubah dengan memberikan kesedaran kepada mereka akan pentingnya pendidikan, penglibatan dalam bidang ekonomi dan sosial yang akan mengangkat mereka ke arah kemajuan. Oleh itu, guru-guru wanita Melayu ini sering mengadakan perjumpaan tidak rasmi antara mereka bagi membincangkan isu-isu wanita dan kemajuan. ${ }^{7}$

Sekolah-sekolah Perempuan Melayu di Johor telah dijadikan sebagai tempat untuk mereka bertemu, berbincang dan berbahas. 
Pergerakan Persekutuan ini sangat menarik kerana mendapat naungan daripada Raja dan Penghulu. Persatuan Perempuan Melayu Johor ini mempunyai beberapa objektif dan antaranya ialah untuk menerbitkan majalah Bulan Melayu. Penerbitan majalah Bulan Melayu ini bertujuan untuk mendidik kaum ibu dan kanak-kanak sama ada lelaki atau perempuan yang bersekolah atau tidak bersekolah, mengumpulkan ibu-ibu dan kanak-kanak perempuan agar mereka bersatu untuk kemajuan, mengadakan majlis perbahasan bagi membuka minda ibuibu dan wanita Melayu serta memajukan wanita Melayu dalam bidang perusahaan melalui wang persatuan. ${ }^{8}$ Akhirnya pada 1 Jun 1930 , Bulan Melayu dengan rasminya diterbitkan di Johor Bahru dengan pengarangnya Hajjah Zainun Binti Sulaiman (Ibu Zain).

Bulan Melayu merupakan majalah bulanan yang menggunakan tulisan Jawi dan terbit selama lebih kurang lapan tahun iaitu bermula dari Jun 1930 hingga Julai 1938. Kejayaan Bulan Melayu disebabkan oleh majalah tersebut dilanggan oleh semua guru lelaki dan wanita seluruh Tanah Melayu. Dengan ini, idea untuk memaju dan menyedarkan kaum wanita telah tersebar ke seluruh pelusuk Tanah Melayu. Penerbitan majalah Bulan Melayu ini diakui oleh pengarang Al-Ikhwan yang menyatakan bahawa majalah Bulan Melayu sebagai majalah pertama yang diterbitkan oleh kaum wanita. Dalam hal ini, Al-Ikhwan merasa bangga kerana wanita telah semakin maju hasil daripada seruan Bulan Melayu. ${ }^{9}$

Usaha-usaha ke arah memartabatkan wanita Melayu pada zaman penjajahan terutamanya dalam bidang pendidikan bukan sahaja dibincangkan dengan mendalam oleh majalah Bulan Melayu, malah usaha ini turut dilakukan bersama-sama dengan akhbar dan majalah lain yang seusia dengannya seperti Majalah Guru, Cenderamata serta Saudara. Persoalan pendidikan merupakan isu pokok yang dibincangkan dalam majalah Bulan Melayu terutama pendidikan kepada kaum wanita kerana mereka diibaratkan sebagai pendidik kepada anak bangsa agar dapat bersaing dengan bangsa-bangsa asing. Dalam hal ini, Bulan Melayu berpendapat punca yang menyebabkan wanita Melayu terkebelakang ialah kerana wanita Melayu tidak mempunyai pendidikan. Selain dapat meningkatkan kedudukan wanita Melayu agar setanding dengan bangsa asing, pendidikan juga akan dapat menaikkan martabat wanita agar setanding dengan kaum lelaki. Menurut pengarang Bulan Melayu:

Kita sudah tahu tidak ada ubat yang sebenar bagi diri dan kaum kita ialah pelajaran. Adakah kita dan kaum kita ada lebih baik keadaannya daripada kelmarin? Lihatlah bangsa Sakai pun sudah bersekolah. ${ }^{10}$ 
Pada ketika itu, pendidikan dalam kalangan wanita Melayu sangat jauh ketinggalan sekiranya dibandingkan dengan golongan lelaki. Walaupun jumlah kaum wanita yang mendapat pendidikan bertambah pada setiap tahun, namun jumlah tersebut masih lagi tidak dapat menandingi jumlah kaum lelaki. Keadaan ini jelas dapat dilihat dalam jadual 1 dan 2 di bawah:

Jadual 1: Jumlah Kanak-kanak Perempuan Yang Bersekolah di Negeri-negeri Bersekutu dan Negeri-negeri Selat Bagi Tahun 1928

\begin{tabular}{|lccc|}
\hline Sekolah Perempuan & Murid & $\begin{array}{c}\text { Murid } \\
\text { Perempuan } \\
\text { di Sekolah Lelaki }\end{array}$ & $\begin{array}{c}\text { Jumlah } \\
\text { Kanak-kanak } \\
\text { Perempuan Yang } \\
\text { Bersekolah }\end{array}$ \\
\hline Negeri Persekutuan & 3,863 & 2,948 & 6,811 \\
Negeri Selat & 2,203 & 546 & 2,749 \\
\hline Jumlah & 6,066 & 3,494 & $\mathbf{9 , 5 6 0}$ \\
\hline
\end{tabular}

Sumber: Bulan Melayu, Jun 1930, hlm. 9.

Jadual 2 : Jumlah Kanak-kanak Lelaki Yang Bersekolah di Negeri-negeri Bersekutu dan Negeri-negeri Selat Bagi Tahun 1928

\begin{tabular}{|lcc|}
\hline Sekolah & Jumlah & Jumlah Murid \\
\hline Negeri Persekutuan & 413 & $\begin{array}{c}28,892 \\
\text { Negeri Selat }\end{array}$ \\
& 176 & $\begin{array}{c}17,852 \text { (termasuk 2 buah } \\
\text { sekolah Labuan) }\end{array}$ \\
\hline Jumlah & 589 & $\mathbf{4 6 , 2 4 4}$ \\
\hline
\end{tabular}

Sumber: Bulan Melayu, Jun 1930, hlm. 10.

Dari jadual di atas, dapat dilihat perbandingan antara kanakkanak perempuan dan juga kanak-kanak lelaki yang berpendidikan. Jumlah kanak-kanak lelaki mengatasi jumlah kanak-kanak perempuan dalam pendidikan iaitu murid lelaki berjumlah 46,244 orang sedangkan murid perempuan hanya berjumlah 9,560 orang pada tahun 1928 . Untuk itu, Bulan Melayu telah menyeru agar kaum wanita bersamasama merebut peluang dalam bidang pendidikan agar mereka juga dapat maju seperti kaum lelaki. Selain itu, pengarang Bulan Melayu juga menyatakan bahawa masyarakat Melayu terutamanya wanita perlu menjadikan wanita bangsa asing khususnya masyarakat Cina sebagai contoh di atas kesungguhan mereka dalam mendapatkan pendidikan walaupun tanpa mendapat bantuan daripada mana-mana 
pihak walaupun pihak kerajaan. Sekolah aliran Cina tetap berkembang seperti mana sekolah Melayu. Ini dapat dilihat pada Jadual 3 di bawah:

Jadual 3: Sekolah Cina Dalam Tahun 1928

\begin{tabular}{|lccccc|}
\hline Negeri & Sekolah & $\begin{array}{c}\text { Jumlah } \\
\text { Murid }\end{array}$ & $\begin{array}{c}\text { Murid } \\
\text { Lelaki }\end{array}$ & $\begin{array}{c}\text { Murid } \\
\text { Perempuan }\end{array}$ & $\begin{array}{c}\text { Bilangan } \\
\text { Guru }\end{array}$ \\
\hline Negeri Selat & 335 & 22,591 & 17,888 & 4,703 & 963 \\
Negeri Melayu Bersekutu & 361 & 21,370 & 16,156 & 5,214 & 839 \\
\hline Jumlah & 696 & 43,961 & 34,044 & 9,917 & 1,802 \\
\hline
\end{tabular}

Sumber: Bulan Melayu Jun 1930, hlm. 12.

Jadual 3 di atas menunjukkan perkembangan sekolah Cina pada peringkat awal tidak banyak perbezaan sekiranya dibandingkan dengan sekolah Melayu. Perkembangan sekolah Cina pada masa ini kebanyakannya adalah atas usaha mereka sendiri iaitu dengan membina sekolah dan menyediakan guru-guru atas perbelanjaan mereka sendiri. Menurut Kua Kia Soong:

The independence of the Chinese education in Malaya by then had been brought about, in part, by the indifference of the colonial administration. It was the only major school system in the Federated Malay States and the Straits Settlements which did not depend on Federal government for financial assistance. ${ }^{11}$

Pertambahan sekolah dan jumlah kanak-kanak Cina yang bersekolah pada masa ini adalah disebabkan oleh pertambahan jumlah bangsa Cina yang bekerja dan menetap di sini. Pada tahun 1930, jumlah imigran Cina yang datang ke Tanah Melayu berjumlah 242,149 orang. ${ }^{12}$ Kebanyakan mereka tinggal di pekan-pekan atau di bandar-bandar besar. Keadaan ini memudahkan mereka untuk menghantar anakanak mereka ke sekolah sama ada ke sekolah Cina atau ke sekolah Inggeris. Manakala bagi orang Melayu pula, kebanyakan daripada mereka tinggal di kawasan pedalaman dan juga di kampung-kampung. Hal ini menyukarkan mereka untuk menghantar anak-anak mereka ke sekolah terutamanya kanak-kanak perempuan. Walau bagaimanapun, ini bukanlah alasan yang menyebabkan masyarakat Melayu tidak menghantar anak-anak mereka ke sekolah, tetapi disebabkan oleh pemikiran masyarakat Melayu yang masih kurang terbuka mengenai pentingnya pendidikan diberikan kepada anak perempuan mereka. Ini menyebabkan beberapa buah sekolah yang dibina dibiarkan sepi begitu sahaja. Menurut pengarang Bulan Melayu: 
Sekolah-sekolah perempuan Melayu itu beberapa lama tinggal menjadi suatu perkara yang susah hendak memajukannya. Sebuah atau dua buah sekolah perempuan yang mula-mula dibuka di pandang oleh ibu bapa Melayu dengan pandangan syak dan tidak percaya. ${ }^{13}$

Ibu bapa Melayu pada waktu ini juga masih lagi berfikiran bahawa anak perempuan mereka tidak perlu diberikan pendidikan kerana mereka percaya anak-anak mereka tidak perlu untuk menyamai kaum lelaki dalam semua bidang. Selain itu, mereka juga bimbang sekiranya anak-anak perempuan mereka ke sekolah, ia akan bercampur antara lelaki dan perempuan. Bagi mereka, perkara ini tidak boleh diterima oleh adat dan tradisi masyarakat Melayu yang beragama Islam. Walaupun wujud pemikiran tidak senang terhadap sistem pendidikan dan kurang mendapat sambutan dalam kalangan ibu bapa, namun penubuhan sekolah perempuan pada peringkat awal tetap diwujudkan. Ini turut digambarkan oleh Mansur Sanusi yang menyatakan bahawa:

Memberi pelajaran kepada kanak-kanak perempuan ini adalah suatu perkara yang susah kerana kebanyakan orang timur dan orang Melayu khasnya pada zaman dahulu tidak percaya yang perempuan-perempuan patut diberi pelajaran sama seperti lelaki dan mereka tidak mahu melepaskan anak-anak perempuan mereka ke luar rumah bercampur dengan laki-laki. ${ }^{14}$

Selain itu, kaum ibu turut merasa bimbang sekiranya dengan menghantar anak-anak ke sekolah, mereka tidak lagi dapat membantu ibu mereka melakukan kerja-kerja rumah. Menurut pengarang Cenderamata:

Ibu bagi budak-budak perempuan itu sentiasa mendapati anakanaknya yang perempuan berguna membantu kerja-kerja di rumah. Maka ibu bapa yang berpuas hati akan kebaikan dirinya sendiri berfikir ia bahawa anaknya yang perempuan itu tentulah bolehlah bermasak-masak dan jahit-menjahit di rumah sahaja dengan tiada apa-apa lebihnya jika dihantarkannya ia ke sekolah. ${ }^{15}$

Masyarakat Melayu pada waktu ini beranggapan jika diberi pendidikan, ia akan menggalakkan anak-anak perempuan mereka pandai menulis surat cinta dan berkasih sayang. Memetik kata-kata pengarang Cenderamata sebagai berikut: 
Ibu bapa atau penjaga budak-budak perempuan Melayu kebanyakannya masih lagi memikirkan jika kanak-kanak perempuan diberi pelajaran membaca dan menulis nescaya bolehlah kelak menggalakkan surat berkasih dan tipu daya. ${ }^{16}$

Kurangnya kesedaran di kalangan masyarakat Melayu pada ketika ini telah menyebabkan wanita Melayu telah jauh tertinggal ke belakang dalam bidang pendidikan. Menurut pengarang Cenderamata lagi:

Didapati akan perempuan-perempuan kita telah tertinggal 40 tahun di belakang lelaki. Jarang benarlah mereka itu tahu menulis dan membaca di dalam bahasanya sendiri. Jauh sekali daripada pandai di dalam hal kira-mengira, ilmu alam dan tawarikh dan terlebih jauh lagilah pula mereka itu daripada mengetahui bahasa asing. ${ }^{17}$

Untuk menyedarkan ibu bapa mengenai pentingnya pendidikan terhadap wanita Melayu, pengarang Cenderamata menyarankan agar tugas menyedarkan ibu bapa dilakukan secara beransur-ansur. Dalam hal ini, Mohd Yusof Ahmad telah mengemukakan beberapa kaedah untuk menarik minat orang Melayu iaitu mengubah pemikiran orangorang tua di kampung-kampung dengan menggunakan contoh dan tauladan. Mereka perlulah diberi nasihat secara perlahan-lahan dengan beberapa kaedah iaitu guru-guru Melayu hendaklah mengadakan hubungan yang baik dengan penghulu dan ketua kampung. Selain itu guru-guru Melayu perlu menjadi contoh kepada orang-orang kampung dengan mempunyai kelakuan yang baik, bersopan santun dan sebagainya dan akhir sekali guru-guru Melayu perlu keluar ke kampung-kampung dan bersyarah memberi nasihat kepada wanitawanita Melayu mengenai pentingnya pendidikan. ${ }^{18}$ Selain Bulan Melayu, akhbar Lembaran Guru juga menyeru agar wanita Melayu diberikan ilmu pengetahuan sebanyak mungkin bagi membolehkan mereka memegang beberapa jawatan penting dalam pentadbiran negara. Menurut Pengarang Lembaran Guru:

Kanak-kanak lelaki itu bakal jadi guru-guru, kerani, pegawai, lawyer, hakim, engineer, datuk, raja, sultan dan lain-lain. Mengapa! Tidakkah kanak-kanak perempuan itu layak dan mampu menjadi bakal penjawat jawatan yang tersebut itu? Apa yang menegah mereka daripada mencapai kemuliaan itu? Ya tidak lain lagi sebabnya ialah kerana memang tidak dilatih diajar mereka itu akan segala perkara itu dan tidak diambil berat sedikitpun oleh pihak yang berkuasa ke atas pelajaran anak-anak perempuannya. ${ }^{19}$ 
Majalah Guru juga tidak ketinggalan memperjuangkan kepentingan pendidikan diberikan kaum wanita Melayu. Ini digambarkan sebagai:

Marilah kita bersungguh-sungguh mengorbankan diri dan masa kita kerana memajukan kaum perempuan bangsa kita daripada darjah kelakuan perbuatan dan keadaan yang rendah tidak bermakna atau tidak berguna seperti kebanyakkannya malas belajar dan malas membaca surat-surat khabar, majalah dan kitabkitab, suka bersenang-senang dengan tiada pelajaran yang dapat memberi faedah kepada kaumnya. ${ }^{20}$

Menubuhkan pendidikan dan pengetahuan yang boleh menerbitkan latihan dan asuhan yang sempurna dan menubuhkan peluang pekerjaan dan kehidupan yang boleh melapangkan pencarian kaum perempuan Melayu. ${ }^{21}$

Kenyataan ini juga telah disokong oleh pengarang akhbar Warta Malaya yang menggalakkan agar wanita Melayu diberikan pelbagai ilmu untuk membimbing alam rumahtangga dan juga untuk diri mereka sendiri. Ini dinyatakan sebagai:

Perempuan kita sangat kekurangan dalam hal pelajaran seperti ilmu berumahtangga, ilmu mengasuh anak, ilmu kebersihan, ilmu masak-memasak, cuci-mencuci, kait-mengait, anyam-menganyam dan lain-lain. ${ }^{22}$

Dalam hal ini, guru-guru Melayu menyarankan agar orang Melayu menjadikan wanita di negara Jepun sebagai contoh kerana di Jepun, kaum wanita telah ramai diberikan pendidikan. Pada tahun 1931, terdapat sebanyak 857 buah sekolah tinggi (sekolah peringkat kedua) telah dibina di negeri Jepun. Selain itu, pada 1930-an terdapat sebanyak lapan buah kolej sendiri telah ditubuhkan (bukan didirikan oleh kerajaan) kepada pelajar wanita telah dibuka. Pelajar-pelajar wanita tersebut boleh menerima pelajaran yang serupa dengan pelajaran di Universiti. Di antara kolej tersebut adalah Tasuda College, Japan Womens University, Medical College, Kobe College, Doshitta College dan Kristian College. ${ }^{23}$

Sekiranya dilihat dari segi sejarah, Penubuhan Penang Free School pada tahun 1816 di Pulau Pinang telah merintis jalan ke arah penubuhan sekolah untuk kaum wanita. Untuk memperkembangkan lagi pendidikan dalam kalangan anak-anak Melayu pada ketika itu, kerajaan British dikatakan telah memberikan kebenaran kepada keluarga di raja Johor khasnya untuk memulakan sekolah berbahasa tempatan bagi kanak-kanak Melayu dan sekaligus menjadi penaung 
kepada sekolah perempuan Melayu yang didirikan di Teluk Belanga, Johor Bahru pada tahun 1883.24

Pada tahun 1884 pula, sebanyak empat buah sekolah perempuan berbahasa tempatan telah dibuka di Singapura. Walau bagaimanapun, sekolah ini juga mengalami masalah kekurangan guru dan murid. Manakala di Pulau Pinang, pada tahun 1889 sebuah lagi sekolah perempuan telah didirikan di Kedah Road yang diberikan oleh Gabenor Pulau Pinang. Namun, sekolah tersebut juga mengalami masalah yang sama. Sistem pendidikan ini diperkembangkan lagi ke negeri yang lain seperti di Melaka dan Selangor pada awal abad ke20. Untuk menyelaraskan lagi pendidikan untuk kaum wanita, satu jawatan telah diluluskan oleh pihak British iaitu jawatan Penyelia Wanita Sekolah Perempuan Melayu yang telah dilantik pada tahun 1918. Tugas penyelia ialah untuk mengawasi pelajaran jahit-menjahit, masak-memasak dan menganyam bakul. ${ }^{25}$ Manakala di negeri Selangor telah ditubuhkan Malay Girl College. Cadangan penubuhan kolej ini adalah dibuat oleh Sultan Selangor iaitu Sultan Salahuddin Alam Shah Ibni Almarhum Sultan Sulaiman Shah pada 25 November 1939 di dalam Majlis Raja-raja. Walau bagaimanapun, pelaksanaannya ditunda apabila Tanah Melayu ditawan oleh Jepun. Kolej Perempuan Melayu hanya dimulakan pada 1 November 1947 oleh Lady Gent (isteri Gabenor Malayan Union). ${ }^{26}$

Manakala di negeri Melaka pula, jika dilihat pada perangkaan tahun 1901-1918, terdapat sejumlah 164 buah sekolah perempuan dengan hitung panjang kehadiran seramai 2,966 orang murid. Jika dilihat dari segi jumlah kanak-kanak perempuan yang belajar di sekolah Inggeris pada tahun 1922, terdapat sekurang-kurangnya lima orang murid yang didaftarkan. Walau bagaimanapun, jumlah tersebut semakin meningkat pada tahun 1935 iaitu sebanyak 21 orang dan meningkat lagi pada tahun 1938 iaitu seramai 30 orang. ${ }^{27}$ Manakala dari segi pendidikan tinggi pula, didirikan Maktab Perempuan Melayu Melaka pada tahun 1935. Maktab tersebut merupakan maktab terulung yang dibina khas untuk wanita Melayu. Penubuhan maktab ini sesungguhnya memberi peluang kepada wanita Melayu mendapatkan pendidikan tinggi dan sekaligus menjadi seorang pendidik kepada bangsanya setelah menamatkan pengajiannya. Dengan penubuhan maktab ini juga, kaum wanita Melayu dapat menyambung pengajian mereka ke peringkat yang paling tinggi kerana sebelum ini, mereka tidak berpeluang untuk memperoleh pendidikan selain pendidikan sekolah rendah. Apa yang nyata, penubuhan Maktab Perempuan Melayu Melaka telah menampakkan tradisi pemingitan wanita Melayu sudah hilang dan wanita Melayu pada ketika itu boleh berbangga 
dengan pendidikan yang diterima oleh mereka walaupun mereka tidak berpeluang untuk melanjutkan pelajaran ke luar negara.

\section{Pendidikan Inggeris untuk Wanita Melayu}

Bulan Melayu juga turut menekankan kepentingan pendidikan Inggeris diberikan kepada kaum wanita Melayu. Ini kerana pendidikan Inggeris sangat penting untuk menaikkan kedudukan kaum wanita Melayu dalam bidang ekonomi dan sosial. ${ }^{28}$ Ketinggalan kaum wanita Melayu dalam pendidikan Inggeris ini juga dapat dilihat apabila membuat perbandingan antara wanita Melayu dan bukan Melayu. Ini dapat dilihat pada jadual 4 dan 5 di bawah:

Jadual 4: Kanak-kanak Perempuan di Sekolah Inggeris Tahun 1928

\begin{tabular}{|lccc|}
\hline Bangsa & $\begin{array}{c}\text { Negeri-negeri } \\
\text { Melayu }\end{array}$ & $\begin{array}{c}\text { Negeri-negeri } \\
\text { Selat }\end{array}$ & Jumlah \\
\hline Melayu & 109 & 80 & 187 \\
Serani & 481 & 1,421 & 1,902 \\
Cina & 2,087 & 3,843 & 5,903 \\
India & 916 & 349 & 1,265 \\
Lain-lain & 166 & 197 & 363 \\
\hline Jumlah & 3,759 & 5,890 & 9,649 \\
\hline
\end{tabular}

Sumber: Bulan Melayu, Jun 1930, hlm.11.

Jadual 5: Kanak-kanak Perempuan di Sekolah Inggeris Tahun 1929

\begin{tabular}{|lccc|}
\hline Bangsa & $\begin{array}{c}\text { Negeri-negeri } \\
\text { Melayu }\end{array}$ & $\begin{array}{c}\text { Negeri-negeri } \\
\text { Selat }\end{array}$ & Jumlah \\
\hline Melayu & 155 & 93 & 248 \\
Serani & 467 & 1,474 & 1,941 \\
Cina & 2,485 & 4,110 & 6,595 \\
India & 888 & 431 & 1,430 \\
Lain-lain & 190 & 197 & 387 \\
\hline Jumlah & 4,297 & 6,305 & 10,601 \\
\hline
\end{tabular}

Sumber: Bulan Melayu, Januari 1931, hlm. 259.

Daripada jadual 5 di atas menunjukkan jumlah kanak-kanak perempuan Melayu yang berpendidikan Inggeris pada tahun 1929 adalah berjumlah 248 orang berbanding dengan bangsa Serani 1,941 orang, Cina 6,595 orang, dan India 1,430 orang. Begitu tinggi jurang 
perbezaan dan ini menunjukkan betapa jauh wanita Melayu ketinggalan dalam pendidikan Inggeris. Keadaan ini menggambarkan kaum wanita Melayu masih ketinggalan jika dibandingkan dengan bangsa asing khususnya bangsa Cina. Keadaan ini mungkin mempunyai kaitannya dengan sikap ibu bapa Melayu pada waktu itu untuk menghantar anak-anak mereka ke sekolah (khususnya sekolah Inggeris) kerana mereka bimbang anak-anak akan terpengaruh dengan ajaran Krisitan. Perkara Ini diperakui sendiri oleh Za'ba dengan menyatakan bahawa:

Ada pun zaman belum beberapa tahun yang lalu kebanyakan bangsa Melayu kita tersangatlah menghinakan dan menakuti anak-anak daripada dihantar ke sekolah-sekolah Inggeris kerana di sekolah-sekolah Inggeris itu sudah tentu tidak ada pelajaran agama Islam maka bertambah pula tiada banyaknya sebab diajarkan bahasa Nasara iaitu bahasa suatu jenis kafir yang sangat dibenci oleh muslimin. Mereka itu memikirkan kalau mati anak itu kelak di dalam kafir kerana siapa tahu entah berpaling kepada ugama Nasara itu apabila dibacanya kitab ugama itu. ${ }^{29}$

Bangsa asing seperti Cina dan India pada waktu ini telah berjaya memasuki Kolej Perubatan dan menjadikan kedoktoran sebagai karier mereka sedangkan wanita Melayu pada ketika itu, masih tidak mampu untuk membaca suratkhabar. ${ }^{30}$ Dalam hal ini, Bulan Melayu menyedarkan kaum wanita Melayu dan bangsa Melayu amnya agar tidak mudah mengalah. Menurut pengarang Bulan Melayu:

Tanah Melayu ini negeri kita dan tempat tumpah darah kita dan kita yang awal sampai ke sini. Kita mempunyai Raja dan Datuk di sini. Kita mempunyai sawah padi dan kampong halaman. Mengapa pula dan apasal kita membiarkan bangsa asing membolot hak-hak yang sepatutnya dipunyai oleh bangsa Melayu. ${ }^{31}$

Walaupun terdapat kekurangan wanita Melayu dalam menerima pendidikan Inggeris, namun di negeri Johor misalnya pendidikan Inggeris dalam kalangan murid-murid telah memperlihatkan perkembangan yang agak baik (lelaki dan perempuan). Hal ini dapat dilihat pada tahun 1930 di antara murid-murid yang mengambil peperiksaan "Cambridge Local", didapati seramai sembilan orang telah lulus peperiksaan "Senior" dan 15 orang telah lulus di peringkat "Junior." Sekolah-sekolah Inggeris ini dikembangkan lagi dengan terbinanya sekolah-sekolah Inggeris di Muar, Johor Bahru dan Segamat. Malah kemajuan pendidikan di sekolah-sekolah Inggeris di Johor juga telah mendapat pujian daripada Stamford Raffles. 
Dilaporkan bahawa dalam peperiksaan "Normal Class" bagi Negerinegeri Selat dan Negeri-negeri Melayu Bersekutu, terdapat seramai 18 orang daripada 20 orang guru-guru Johor yang mengambil peperiksaan telah lulus dalam peperiksaan tersebut. Dalam peperiksaan "Cambridge" dilaporkan sebanyak 85 peratus telah lulus peringkat "Senior" dan 43 peratus telah lulus di peringkat "Junior". Pada tahun ini juga, terdapat sebanyak dua buah sekolah Inggeris telah dibina iaitu "English College" dan Sekolah Inggeris yang dibuka di Segamat. ${ }^{32}$

\section{Pendidikan Agama untuk Wanita Melayu}

Selain pendidikan sekular dan pendidikan Inggeris, akhbar dan majalah Melayu pada ketika itu juga turut menekankan agar kaum wanita Melayu diberi pendidikan agama yang secukupnya. Dalam hal ini, mereka berpendapat walaupun pendidikan sekular itu penting, namun pendidikan agama tidak boleh dipisahkan daripada pendidikan sekular. Justeru itu, dalam sekolah-sekolah wanita juga perlu diadakan pendidikan agama sebagai salah satu dari mata pelajaran sekolah. ${ }^{33}$ Pendidikan agama perlu ditekankan kerana masyarakat Melayu kerana mereka masih percaya kepada amalan karut, animisme, perbalahan antara umat Islam dan sebagainya. Malah terdapat juga dalam kalangan masyarakat Melayu yang terlalu mementingkan pendidikan agama sahaja dan menolak pendidikan sekular. Terdapat juga di antara mereka yang mementingkan pendidikan sekular dan membuang pendidikan agama kerana menganggap ilmu sekular penting untuk mengejar kemodenan. Pemikiran seperti inilah yang telah membawa masyarakat Melayu menjadi mundur kerana salah tafsiran antara konsep Islam dan pemodenan. Oleh itu, pendidikan agama perlu diberikan kepada kaum wanita untuk melahirkan wanita Melayu yang berilmu dan juga beraga ma. Menurut pengarang Bulan Melayu, hampir 90 peratus kaum ibu Melayu jahil dalam ilmu agama. ${ }^{34}$ Penulis mengatakan demikian mungkin pendidikan agama yang diterima secara tidak formal masih tidak mencukupi untuk mendidik wanita Melayu mengenai hal-hal keagamaan.

\section{Kesimpulan}

Perkembangan persuratkhabaran Melayu dalam tempoh 1920-1940an sememangnya memberi impak kepada masyarakat Melayu yang masih berada di bawah penjajahan British. Dalam tempoh ini dapat dilihat akhbar dan majalah dijadikan sebagai "alat" untuk menyedarkan masyarakat Melayu betapa pentingnya pendidikan khususnya kepada wanita Melayu. Jelas dapat dilihat dalam tempoh 
ini terdapat golongan intelektual Melayu sama ada yang berpendidikan agama, Inggeris dan Melayu yang memainkan peranan penting sebagai agen kerajaan untuk memajukan masyarakat Melayu.

Daripada apa yang telah dibincangkan didapati pendidikan mendasari perjuangan golongan intelektual pada waktu ini. Bentuk pendidikan yang dimaksudkan adalah pentingya pendidikan Inggeris dan pendidikan agama diberikan kepada wanita Melayu. Penekanan diberikan kepada dua bentuk pendidikan ini adalah bagi memastikan wanita Melayu juga mampu bersaing dengan kaum lelaki dan juga bangsa asing. Manakala pendidikan agama adalah perlu untuk memastikan wanita Melayu mempunyai ilmu agama yang mencukupi bagi menempuh arus kemodenan. Tidak dilupakan dengan adanya pendidikan ia dapat meningkatkan taraf sosial wanita Melayu agar dapat memasuki alam pekerjaan dan tidak hanya menjadi suri rumahtangga sahaja.

Usaha golongan intelektual menyedarkan masyarakat Melayu mengenai pentingnya pendidikan merupakan satu cabaran kerana pada waktu ini masyarakat Melayu masih lagi tidak memahami akan kepentingan pendidikan kepada wanita, masih menganggap anakanak perempuan mereka perlu menjadi penolong ibu-ibu mereka menguruskan rumah tangga, syak wasangka terhadap pendidikan Inggeris kerana takut terpengaruh dengan ajaran Kristian serta masih menganggap kaum wanita tidak perlu mendahului lelaki dalam semua bidang. Wanita Melayu pada waktu ini sangat jauh ketinggalan berbanding bangsa asing dalam pendidikan khususnya dalam pendidikan Inggeris.

\section{Nota}

Abdullah bin Abdul Kadir, The Hikayat Abdullah (Terj.) oleh A.H. Hill, London: Oxford University Press, 1970, hlm. 80-81.

Abdullah Haji Jaafar, 'Al-Imam', Latihan Ilmiah, Universiti Malaya, Kuala Lumpur, 1971/1972, hlm. 50.

Marina Merican, 'Syed Sheikh Al-Hadi dan Pendapatnya Mengenai Kaum Perempuan,' Latihan Ilmiah, Universiti Malaya, Kuala Lumpur, 1960, hlm. 308.

Ibid.

Sebelum Perang Dunia Kedua, salah seorang wanita yang sangat cemerlang dalam sejarah perjuangan kaum wanita ialah Hajah Zainun binti Sulaiman atau lebih dikenali sebagai Ibu Zain. Atas daya usaha beliau juga telah ditubuhkan Persekutuan Guru-guru Perempuan Melayu Johor pada tahun 1930 dan menerbitkan majalah Bulan Melayu sebagai lidah rasmi perjuangan mereka. Ekoran daripada ini, beliau telah digelar sebagai "Ibu Pembebasan Wanita Melayu" oleh masyarakat Melayu. 
6 Shaharom Husain, 'Peranan Bulan Melayu dan Tokoh-tokohnya Dalam Perkembangan Bahasa dan Persuratan Melayu, Institut Bahasa dan Kesusastraan Melayu, Universiti Kebangsaan Malaysia, 1987 (tiada halaman). Menurut beliau, sebelum ini telah wujud majalah untuk wanita seperti Dewan Perempuan (1935) dan Dunia Perempuan (1936) yang diterbitkan di Singapura. Namun, majalah ini tidak dapat mengatasi pengaruh yang dilakukan oleh Bulan Melayu. Dalam hal ini, Bulan Melayu turut mendapat langganan tetap dan usianya lebih lama sekiranya dibandingkan dengan majalah-majalah wanita yang lain. Kehadiran Bulan Melayu bukan sahaja mendapat sokongan daripada pihak guru, murid-murid sekolah, dan ibu bapa malahan telah mendapat sokongan daripada pelbagai pihak seperti Raja-raja, Tuan Besar, Penghulu dan juga dari pengarang akhbar lain seperti Majalah Guru, Al-Ikhwan, Saudara, Lembaga Melayu, Dunia Melayu, Cenderamata, Semangat Islam, Warta Malaya dan Lidah Benar.

7 Dalam mesyuarat pertama diadakan pada 20 Januari 1930 di Johor Bahru dan kali kedua di Batu Pahat pada 25 April 1930, kata sepakat telah dicapai bagi menubuhkan Persekutuan. Pada mesyuarat yang sama juga, pandangan telah disuarakan untuk menerbitkan sebuah majalah yang dinamakan Bulan Melayu yang akan dijadikan sebagai lidah rasmi bagi menyalurkan kesedaran kepada kaum wanita untuk maju. Oleh itu, pada 1 Jun 1930, Persekutuan Perempuan Melayu Johor telah didaftarkan secara rasmi dan ahlinya berjumlah lebih kurang 100 orang. Mereka terdiri daripada guru-guru wanita Melayu Johor dan dibantu oleh ahli-ahli yang lain. Bulan Melayu, Jun 1930, hlm. 5. Bulan Melayu, 1 Julai 1930, hlm. 40.

$9 \quad$ Al-lkhwan, Mac 1930, hlm. 213-214.

10 Bulan Melayu, Jun 1935, hlm. 26.

11 Kua Kia Soong, The Chinese Schools of Malaysia, A Protean Saga, The Resource and Research Centre, Selangor Chinese Assembly Hall, Kuala Lumpur, 1985, hlm. 31.

12 Annual Report Straits Settlements 1930, hlm. 910.

13 Bulan Melayu, Januari 1931, hlm. 260. Menurut sumber kolonial pula mereka menyatakan bahawa, ibu bapa Melayu beranggapan dengan memberikan pengetahuan membaca dan menulis akan menggalakkan anak-anak mereka menulis surat cinta dan asyik masyuk. Selain itu, ibu bapa juga takut membiarkan anak perempuan mereka berjalan keseorangan tanpa ditemani oleh seseorang muhrim. Manakala kaum ibu juga takut kehilangan anak-anak perempuan mereka untuk membantu kerja-kerja memasak dan kerja-kerja rumah.

14 Mansur Sanusi, Sejarah Perkembangan Pelajaran Melayu, Pulau Pinang, 1955, hlm. 5.

15 "Sekolah Melayu Perempuan", Cenderamata, Jun 1924, hlm. 95.

16 Ibid.

17 Cenderamata, November 1923, hlm.71. 
18 Mohd Yusof Ahmad, "Pelajaran di Negeri Jepun" (Pelajaran Perempuan dan Perempuan perempuannya yang baru), Majalah Guru, April 1934, hlm. 123-124.

19 "Kewajipan Perempuan", Lembaran Guru, Februari/Mac 1927, hlm. 42 "Penggugat Perasaan Guru-guru Perempuan", Majalah Guru, Julai 1934, hlm. 247.

21 "Pelajaran dan Pekerjaan Anak-anak Perempuan Melayu", Majalah Guru, Mac 1938, hlm. 87-88.

22 Ham Maayun, "Harapan Kita Kepada Guru-guru Perempuan Melayu," Warta Malaya, 2 Julai 1938, hlm. 19.

23 Ibid

24 Lenore Manderson, Wanita, Politik dan Perubahan, Fajar Bakti, Kuala Lumpur 1990, hlm. 29. Negeri Johor boleh dikatakan sebagai negeri terawal maju dari segi pendidikan. Ini kerana, dalam tahun 1883 saja sudah terdapat lima buah sekolah Melayu telah didirikan. Antaranya ialah Sekolah Melayu Johor Bahru, Sekolah Melayu Padang Muar dan Sekolah Melayu Tanjung. Manakala pada tahun 1884 telah didirikan pula Sekolah Melayu Bandar Maharani. Diikuti pada tahun 1895, sebuah sekolah Melayu lagi dibuka di Kota Tinggi iaitu Sekolah Melayu Bandar Kota Tinggi. Pendidikan di Negeri Johor berkembang lagi pada abad ke-20 dan beberapa buah sekolah perempuan telah didirikan khusus untuk memberikan pendidikan kepada perempuan Melayu Johor. Sekolah Melayu perempuan pertama didirikan di Johor ialah Sekolah Perempuan "Sukapeti" yang didirikan di Muar pada tahun 1911. Perkembangan pendidikan di Negeri Johor juga dapat dilihat berdasarkan kenyataan Ringkasan Pejabat Pelajaran Johor yang disiarkan dalam Bulan Melayu bagi tahun 1930-1931. Didapati terdapat pertambahan dalam jumlah kemasukan murid ke sekolah-sekolah iaitu daripada 15,145 orang pada tahun 1930 kepada 15,917 orang pada tahun 1931. Mengikut kenyataan pada tahun 1931, pertambahan kedatangan murid lelaki sekolah Melayu adalah daripada 88 peratus pada tahun 1929 kepada 95 peratus pada tahun 1930. Begitu juga dengan sekolah agama telah menunjukkan pertambahan bilangan murid-murid, malah dari segi kedatangan dan peperiksaan telah menunjukkan kemajuan. "Ringkasan Kenyataan Tahun 1930 Bagi Pejabat Pelajaran Johor," Bulan Melayu, Februari 1931, hlm. 298.

26 Rashila Ramli, "Wanita Melayu Zaman Kolonial: Kajian Kes di Kolej Perempuan Melayu (1947-1956)", Seminar Kedudukan Cinta dan Indentiti Wanita Melayu Zaman: Kolonial, Universiti Kebangsaan Malaysia, 1415 Julai 1998, hlm.13. Jika ditinjau dari segi perkembangan pendidikan perempuan di sekolah Selangor pada akhir tahun 1928, sudah terdapat sembilan buah sekolah termasuk tiga buah sekolah yang baru dibina iaitu di Segambut, Petaling, Seputih dan Klang. Bilangan kanak-kanak perempuan di sekolah perempuan pada akhir tahun 1928 berjumlah 562 orang, manakala bilangan kanak-kanak perempuan di sekolah lelaki berjumlah 814 orang iaitu berlaku pertambahan sebanyak 169 
orang daripada tahun 1927. "Perkhabaran Sekolah-Selangor," Cenderamata, April 1929, hlm. 10.

27 Aida binti Yusof, 'Maktab Perguruan Perempuan Melayu Melaka 19351993', Latihan Ilmiah, Universiti Kebangsaan Malaysia, Selangor, 1992/ 93, hlm. 9.

28 Pada masa ini, kepandaian berbahasa Inggeris merupakan aset untuk meningkatkan mobilisasi sosial. Sesiapa yang pandai berbahasa Inggeris akan memudahkan mereka memohon pekerjaan dengan pihak Kerajaan.

29 Surat Persendirian Za'ba, "Anak-anak Melayu di Sekolah Inggeris," Jun 1954, hlm.12 dalam SP 18/1A/4/9, Arkib Negara Malaysia Kuala Lumpur. Perkara ini mungkin ada kebenarannya kerana berdasarkan rakaman temuramah yang diadakan oleh Arkib Negara dan Hajjah Zainun atau Ibu Zain, beliau menceritakan pengalamannya semasa bersekolah di sekolah Inggeris dan sememangnya di sekolah Inggeris ada mengajar mengenai agama Kristian.

30 Bulan Melayu, Januari 1931, hlm. 259.

31 Bulan Melayu, Jun 1930, hlm. 11-12.

32 H.R. Cheesemen, "Risalah Kenyataan Tahun 1930 Bagi Pejabat Pelajaran Johor," Bulan Melayu, Februari 1931, hlm. 299.

33 Perbincangan tentang perkara ini boleh dilihat dalam, "Pelajaran Anakanak Melayu dan adakah Anak-anak Melayu Berhajat Kepada Pelajaran Agama,"Saudara, 15 Nov 1930, "Anak-anak Sekolah Dengan Agama Islam", Saudara, 13 Jun 1931, "Pelajaran Agama di dalam Semenanjung," Majlis, 3 Mac 1932 hlm. 1. "Pelajaran Agama di SekolahSekolah Melayu Selangor,"Majlis, 22 Jan 1934, hlm. 12.

34 Muhamad bin Taib، "Akal dan Kemuliaannya," Bulan Melayu, Februari 1931, hlm. 328. 